\title{
Optimization and Characterization of Ultrasound-Assisted Pectin Extracted from Orange Waste
}

\author{
Ketema Beyecha Hundie \\ School of Chemical Engineering, Jimma University Institute of Technology, Jimma, Ethiopia. \\ *Corresponding Author Email: ketema.hundie@ju.edu.et \\ Received 27 January 2021, Revised 15 August 2021, Accepted 06 October 2021
}

\begin{abstract}
The concept of waste to valuable products is a hot topic with exploring ongoing worldwide to minimize food-based feedstocks. This work utilized a citric acid solution and an ultrasoundassisted to extract pectin from orange waste, a critical agroindustry byproduct. Artificial neural network and central composite design were utilized to assess the extraction of pectin using different levels of the extraction parameters and in turn to optimize the extraction process. The extraction of pectin from orange waste is found to be highly affected by $\mathrm{pH}$ solution and ultrasound power. The result of an artificial neural network was found to be better in terms of prediction capability and performance indexes. Fourier transform infrared spectrometry analysis confirmed the existence of functional groups in the fingerprint region of orange waste pectin. Ash and crude protein content of orange wastes are found to be low; meaning low ash and protein content contributes to better gelling ability of the pectin. The extracted pectin has a higher degree of esterification. The result of the current work highlighted that orange wastes are a good source of pectin. In addition, the extracted pectin from orange wastes can be used as a food additive as it fulfills all the standard requirements pectin for application.
\end{abstract}

Keywords: Characterization, Extraction, Pectin substance, Optimization, Orange waste.

\section{Introduction}

Polybrominated diphenyl ethers (PBDEs) consists of 209 possible substances, Pectin is a complex polysaccharide substance in cell walls of the plant, including a backbone of $\alpha$ 1,4-galacturonic acids that are partly esterified at the carboxylic acid groups [1]. It comprises $25 \%$ of the molecular part in the plants admitting their growth and cell propagation [2]. Depending on the esterified carboxylic acid groups, pectin is classified into two classes with different utilizations: high methoxyl pectin (HMP, esterification degree above 50\%) and low methoxyl pectin (LMP, esterification degree below 50\%) [3]. The existence of the esterified groups and as well as neutral sugars, as the side chains, contribute to developing various contributions covalently connected, that homogalacturonan and xylogalacturonan are the most significant of them [4]. These complex polysaccharides, widely distributed in the cell wall of the plant tissues, have several utilizations in the nutrient industry and pharmaceutical industry (as an antioxidant, anti-diabetic and anti-cancer) [3].

Traditionally, pectin is extracted from citrus waste utilizing hot acidified water that brings destroying and change of its structure which leads to change its natural characteristics [5]. Non-conventional extraction technologies were formulated [6]. Amidst these techniques, ultrasound-assisted extraction is considered as an effective and 
efficient technique, since the influence of ultrasound waves used to ameliorate the destruction of cell wall of the plant and increase the rate of mass transporting for better performance and quality of the product with the short time of extraction [7].

Since it is inexhaustible in pectin, the waste of orange is considered as the essential crude material that plays a critical role in the manufacturing of pectin. Orange natural products areee most utilized by juice preparing businesses, left as squanders each day [1]. Instead of disposing of that material as squanders, it is important to convert it into valuable products, a massive amount of orange wastes are produced every year [8]. Considering the expansive amount of pectins by the orange handler, it would be incredibly useful to utilize this source for manufacturing value-added items. Artificial neural network (ANN) and Central composite design (CCD) models have been highly applied in optimizing various process parameters. However, CCD model is only for a restricted range of input process variables and artificial neural network (ANN) is an excellent tool over CCD for non-linear multivariate [9], a technology that includes several numbers of layers [10].

ANNs are powerful computational and flexible intelligence systems standing for nonlinear regression technique with a good level of robustness to map the nonlinear structures of any problems. As a result, ANNs have found out several applications in detecting nonlinear functional relationships between variables with non-integrated, multidimensional, and nonlinear data sources owing to their the maximum learning ability [11].

An ANN is made from hundreds of single units, artificial neurons or processing elements linked with coefficients (weights), that constitute the neural construction and are formed in the hidden layers [12].

To develop feed forward multilayer back propagation, ANN tool was carried out using MATLAB ${ }^{\circledR}$ 2016a. Therefore, the objective of this study was an optimization of ultrasound-assisted pectin extracted from orange wastes and its characterization using CCD and ANN model. Besides, to study the consequence of process parameters on the result and compare the central composite design and artificial neural network prediction capability and their performance indexes.

\section{Materials and Methods}

The orange wastes were collected from a juice processer in Jimma city, Ethiopia. It was manually cleaned and dried for $36 \mathrm{hrs}$ followed by an electric oven dry at $55{ }^{\circ} \mathrm{C}$ and pretreated [13].

Analytical grade chemicals [Citric acid, $\mathrm{HCl}, \mathrm{H}_{2} \mathrm{SO}_{4}, \mathrm{NaOH}$, ethanol, 2,2Diphenyl-1-Picrylhydrazyl] were purchased from chemical purchasers.

\section{Proximate analysis}

For orange waste characterization, it was determined the moisture contents (MC), ashes contents (AC) and crude protein contents (PC) followed by analytical standards of ASTM method adopted by [14], with modification. The moisture was found out depending on the sample weight loss subjected to heating at $103{ }^{\circ} \mathrm{C}$ until a constant weight was recorded. The ash content corresponds to the residual obtained by burning at temperatures of $550{ }^{\circ} \mathrm{C}$ to get clear light ash. Crude protein was determined by Florencia, et al. [15], method and 6.25 as factor for the protein nitrogen contents. 


\section{Central composite experimental design}

Extraction parameters are selected as shown in Table 1 with coded and actual levels according to pre-study.

Table 1. Central composite design parameters level for pectin extraction.

\begin{tabular}{|c|c|c|c|c|c|c|}
\hline Parameters & Unit & Minimum & Maximum & & Levels & \\
\hline $\begin{array}{l}\text { A: Irradiation } \\
\text { time }\end{array}$ & Min & 15 & 30 & $\begin{array}{c}10 \\
(-1)\end{array}$ & $25(0)$ & $\begin{array}{c}40 \\
(+1)\end{array}$ \\
\hline B: $\mathrm{pH}$ solution & - & 2 & 3 & $\begin{array}{c}2 \\
(-1)\end{array}$ & $2.5(0)$ & $\begin{array}{c}3 \\
(+1)\end{array}$ \\
\hline $\begin{array}{l}\text { C: Ultrasound } \\
\text { power }\end{array}$ & W & 50 & 120 & $\begin{array}{c}50 \\
(-1)\end{array}$ & $85(0)$ & $\begin{array}{l}120 \\
(+1)\end{array}$ \\
\hline $\begin{array}{l}\text { D: Liquid-solid } \\
\text { ratio }\end{array}$ & $\mathrm{mL} / \mathrm{g}$ & $15: 1$ & $25: 1$ & $\begin{array}{l}15: 1 \\
(-1)\end{array}$ & $20: 1(0)$ & $\begin{array}{l}25: 1 \\
(+1)\end{array}$ \\
\hline
\end{tabular}

The second-order models generated by central composite design are shown by Eq. (1).

$Y=y+\sum_{i=1}^{k} \beta_{i} X_{i}+\sum_{i=1}^{k} \beta_{i i} X_{i} X_{i}+\sum_{i=1}^{k-1} \sum_{j=i+1}^{k} \beta_{i l} x_{i} x_{1}+e$

Where, $\mathrm{Y}, \mathrm{x}_{\mathrm{i}}$ and $\mathrm{x}_{\mathrm{j}}, \gamma, \beta_{\mathrm{i}}, \beta_{\mathrm{i}}, \beta \mathrm{ii}, \mathrm{k}$, and $\epsilon$ are anticipated response, input factors, constant term, linear coefficient, quadratic coefficient, interaction term, number of factors, and random error, respectively.

\section{Artificial neural network}

An artificial neural network is an information-processing framework that has certain execution characteristics in mutual with neural network systems. Among different neural network models, the feed-forward neural depend on back-propagation is the most beneficial tool. This network tool has four inputs (irradiation time, ultrasound power, $\mathrm{pH}$, and liquid-solid ratio) and one output (yield of pectin). To prepare the training, input-output data detected from the actual value are divided into $70 \%$ for training, $15 \%$ for test and $15 \%$ for validation [10]. To find out the best training efficiency, input-output was normalized to $[-1,1],[16]$. The normalized data were forwarded to the artificial neural network in feed-forward multilayer backpropagation. After the ANN tool memorizes the data from the training, crossvalidation was applied to prevent an overfit of the training. The best neurons in the hidden layer was decided when the small number of performance indexes have reached. CCD and ANN model performance index evaluation.

The ANN model was tested with 30 data sets of CCD experiments. For each input combination, the anticipated values of pectin yield were compared with the respective test values of the performance indexes such as coefficient of determination value $\left(\mathrm{R}^{2}\right)$, average squared error; MSE, average mean error; AME, prediction of standard error; PSE, and mean absolute difference; MAD as shown in Eqs. $\left(2^{-6}\right)$.

$$
\begin{aligned}
& \mathbf{R}^{2}=1-\sum_{i=1}^{x}\left\lfloor\frac{(p r-e x)^{2}}{(p r-m)^{2}}\right] \\
& \text { MSE }=1-\frac{1}{x} \sum_{i=1}^{x}\left\lfloor(p r-e x)^{2}\right\rfloor \\
& \text { SRP }=\left[\frac{\text { RMSE }}{\mathrm{m}}\right] \\
& \text { AAD }=\frac{100}{\mathrm{x}} \sum_{\mathrm{i}=1}^{\mathrm{r}}\left[\frac{\mathrm{e}_{\mathrm{x}}-\mathrm{p}}{e_{\mathrm{x}}}\right] \\
& \text { MAE }=\sum_{\mathrm{i}=1}^{\mathrm{x}}\left\lfloor\frac{\mathrm{ex}-\mathrm{pr}}{\mathrm{ex}}\right]
\end{aligned}
$$

Where; $x=$ number of run, $p_{r}=$ predicted value, $e_{x}=$ experimental value and $m=$ mean experimental value

\section{Pectin extraction process}

The extraction was carried out utilizing Chua [17], with modification in all runs, and $40 \mathrm{gm}$ of the powdered sample was blended with $\mathrm{pH}$ of $(2-3)$ citric acid solution in a 400 $\mathrm{mL}$ flask. It was then sonicated for $(15-30 \mathrm{~min})$, in the range of $60-140 \mathrm{~W}$, 
ultrasound power, thereafter the mixture was maintained at a temperature of $25^{\circ} \mathrm{C}$ and percolated. The percolate carrying pectin was chilled down, for $20 \mathrm{~min}$ and centrifuged at $7500 \mathrm{rpm}$. Ethanol of $95 \%$ was utilized, to precipitate the supernatant and allowed for 60 min, for flotation of the pectin. The resulting dried pectin was ground too finely pectin and stored for subsequent analysis.

The extracted orange peel pectin yield was calculated on dry basis as follows.

$$
\text { The y̧ield of pectin }(W)=\frac{\text { Weiqutt of extratted pectin }}{\text { Weight of processed driad orange peal powdwr }}: 100(7)
$$

Table 2. Independent parameters, experimental value and yield using RSM and ANN prediction.

\begin{tabular}{|c|c|c|c|c|c|c|}
\hline \multirow[b]{2}{*}{$\begin{array}{c}\text { Run } \\
\text { Order }\end{array}$} & \multicolumn{4}{|c|}{ Factors } & \multirow{2}{*}{$\begin{array}{c}\text { EXP } \\
\%\end{array}$} & \multirow[b]{2}{*}{$\begin{array}{c}\text { Predicted } \\
\%\end{array}$} \\
\hline & $\begin{array}{c}\text { Irrad- } \\
\text { iation } \\
\text { time } \\
(\text { min) }\end{array}$ & $\begin{array}{c}\text { pH } \\
\text { solution }\end{array}$ & $\begin{array}{l}\text { Ultrasound } \\
\text { power }(W)\end{array}$ & $\begin{array}{r}\text { L-S-R } \\
(\mathrm{mL} / \mathrm{g})\end{array}$ & & \\
\hline 1 & 30 & 2 & 120 & 30 & 20.01 & 20.11 \\
\hline 2 & 15 & 3 & 120 & 15 & 9.90 & 10.81 \\
\hline 3 & 22.5 & 2.5 & 85 & 22.5 & 23.23 & 24.16 \\
\hline 4 & 15 & 3 & 50 & 30 & 11.30 & 12.34 \\
\hline 5 & 30 & 3 & 120 & 30 & 10.30 & 11.31 \\
\hline 6 & 30 & 2 & 50 & 15 & 16.30 & 17.55 \\
\hline 7 & 22.5 & 2.5 & 85 & 7.5 & 16.70 & 17.45 \\
\hline 8 & 37.5 & 2.5 & 85 & 22.5 & 7.30 & 8.15 \\
\hline 9 & 30 & 2 & 120 & 15 & 22.57 & 23.51 \\
\hline 10 & 7.5 & 2.5 & 85 & 22.5 & 8.50 & 9.27 \\
\hline 11 & 22.5 & 3.5 & 85 & 22.5 & 5.75 & 6.46 \\
\hline 12 & 22.5 & 2.5 & 85 & 37.5 & 16.70 & 17.55 \\
\hline 13 & 22.5 & 2.5 & 85 & 22.5 & 23.40 & 24.19 \\
\hline 14 & 30 & 2 & 50 & 30 & 15.01 & 15.95 \\
\hline 15 & 22.5 & 2.5 & 50 & 22.5 & 15.80 & 15.55 \\
\hline 16 & 22.53 & 1.52 & 155.6 & 22.51 & 26.5 & 27.13 \\
\hline 17 & 15 & 2 & 50 & 30 & 15.00 & 14.20 \\
\hline 18 & 30 & 3 & 50 & 30 & 10.00 & 11.30 \\
\hline 19 & 15 & 3 & 50 & 15 & 8.31 & 9.72 \\
\hline 20 & 30 & 3 & 50 & 15 & 8.10 & 8.10 \\
\hline 21 & 22.5 & 2.5 & 85 & 22.5 & 23.10 & 24.19 \\
\hline 22 & 15 & 2 & 120 & 30 & 20.54 & 21.65 \\
\hline 23 & 15 & 2 & 120 & 15 & 22.50 & 23.71 \\
\hline 24 & 22.5 & 2.5 & 85 & 22.5 & 23.00 & 24.16 \\
\hline 25 & 15 & 2 & 50 & 15 & 16.40 & 16.2 \\
\hline 26 & 30 & 3 & 120 & 15 & 8.88 & 10.06 \\
\hline 27 & 22.5 & 2.5 & 85 & 22.5 & 22.99 & 24.17 \\
\hline 28 & 22.5 & 2.5 & 85 & 22.5 & 23.40 & 24.19 \\
\hline 29 & 22.5 & 2.5 & 85 & 22.5 & 23.23 & 24.15 \\
\hline 30 & 15 & 3 & 120 & 30 & 11.50 & 13.71 \\
\hline
\end{tabular}

EXP. $=$ Experimental, $\mathrm{CCD}=$ Central composite design

\section{Product Characterization} FT-IR Spectroscopy Detection

The pectin contents were detected utilizing the prink Elmer spectrum 70 FT-IR technique with the help of IR correlation. The wavenumber region for the analysis was 4000 $400 \mathrm{~cm}^{-1}$ and the IR spectrum was reported using percent of transmittance.

\section{Esterification Degree (ED)}

The esterification degree was decided based on the procedure adopted by Chua [17], with modification by utilizing Eq. (8).

$\operatorname{ED}(\%)=\frac{M_{2}}{M_{1}+M_{2}} * 100$

Where, $\mathrm{M}_{1}=$ initial titer volume $(\mathrm{ml})$, and $\mathrm{M}_{2}$ $=$ last titer volume $(\mathrm{ml})$

\section{Equivalent Weight (EW)}

The equivalent weight was calculated utilizing method reported by $\mathrm{H}$. Mohamed [18] including modifications and the percent of the equivalent weight was determined utizinig Eq. (9).

Equivelent weight $(\%)=\frac{\mathbf{W}_{\mathrm{s}} * 1000}{\mathbf{R}_{\mathrm{a}} * \mathrm{Na}_{\mathrm{ne}}}$

Where, $\mathrm{R}_{\mathrm{a}}=$ amount of $\mathrm{NaOH}$ (milliliter), and $\mathrm{Na}_{\mathrm{en}}=$ concentration of $\mathrm{NaOH}$.

\section{Methoxyl determination}

The amount of methoxyl content (MC) was carried out utilizing Sundarraj et al., [19] procedure and its percentage was determined according to Eq. (10).

$$
\mathrm{MC}(\%)-\frac{\mathrm{V}_{\mathrm{a}} * \mathrm{~N}_{\mathrm{a}}+3.1}{\mathrm{ws}_{\mathrm{s}}}
$$




\section{Total an-hydrouronic acid (TAA)}

It was carried out utilizing the procedure adopted by H.Mohamed [18] and its percentage was determined using Eq. (11).

Total anhydrouronic acid content $(\%)=1.76 * \frac{(\mathrm{a}+\mathrm{b})}{\mathrm{m}_{\mathrm{a}}}$

Where, $\mathrm{a}=$ amount of $\mathrm{NaOH}(\mathrm{ml})$ from Eq. (9) and $b=$ amount of $\mathrm{NaOH}(\mathrm{ml})$ from Eq. (10).

\section{Acetyl value}

The Acetyl value of dry pectin was determined using procedure reported from E.Kliemann [20] and percentage of acetyl was determined by Eq. (12).

$$
\text { Acetyl value }(\phi 6)-\frac{v_{\mathrm{a}} \times \mathrm{N}_{\mathrm{a}} \times 4.3}{\mathrm{~m}_{\mathrm{z}}}
$$

\section{Results and Discussion \\ Proximate Analysis}

The orange wastes were analyzed for its proximate analysis using the standard ASTM recommended method. The result of the proximate analysis shows that the moisture content of the orange waste was $10.2 \% \pm 0.01$. This result was expected because the sample has been subjected to drying for $72 \mathrm{~h}$ to minimize the moisture content of the sample.

Ash content and crude protein content of orange wastes were $4.56 \% \pm 0.02$ and 1.72 $\% \pm 0.4$ respectively. According to Asgari et al., [21], low ash and protein content leads to better gelling properties of the pectin. Similar protein content of commercial citrus pectin of $1.76 \% \pm 0.2$ was observed [22]. The crude protein content of pectin extracted by microwave assisted extraction of $1.67-1.74 \%$ was similar to that of the pectin extracted by conventional extraction of $1.65 \%$.
The crude protein content measured was due to the dissolution of nitrogen from the powder of orange waste in the solvent because of the high temperature generated by both ultrasound-assisted extraction and microwave assisted extraction method [23].

Validation of central composite design model optimization for experimental data analysis

A very good correspondence between the observational and anticipated values for pectin yield was obtained from the check bit plot generated by CCD as shown in Fig. 1. Besides, according to Table 2, the extracted minimum and maximum pectin yields were $5.75 \%$ and $26.5 \%$, respectively. As well as at optimal extraction, point; $22.51: 1 \mathrm{~mL} / \mathrm{g}$ ) of liquid-solid ratio, of $1.52 \mathrm{pH}$ solution, 155.6 $\mathrm{W}$ of ultrasound power, and $22.53 \mathrm{~min}$ of extraction time, $27.13 \%$ pectin yield was attained using response surface methodology prediction. By triplicated tests on the stated parameters, the achieved result checked that the anticipated model for extraction process was in high precision the extraction yield of pectin under triplicated optimized point was $27.8 \pm 02 \%$.

This result was confirmed with $28.07 \pm$ $0.67 \%$ of pectin extracted by ultrasoundassisted from sour orange peel at optimal extraction conditions [24]. The variation could be due to; plant source and the extraction technique taken for the separation process [25]. Remarkably, the extraction yield of pectin in this study was greater than the described results for the extracted pectin from apple pomace using microwave-assisted extraction technique by Asgari et al., [21], using a conventional technique $(15.75 \%)$, by Chen et al. [24], from dragon fruit peel using microwave-assisted extraction technique 
(7.50\%) and by Methacanon [4] using by conventional technique $(8.80 \%)$.

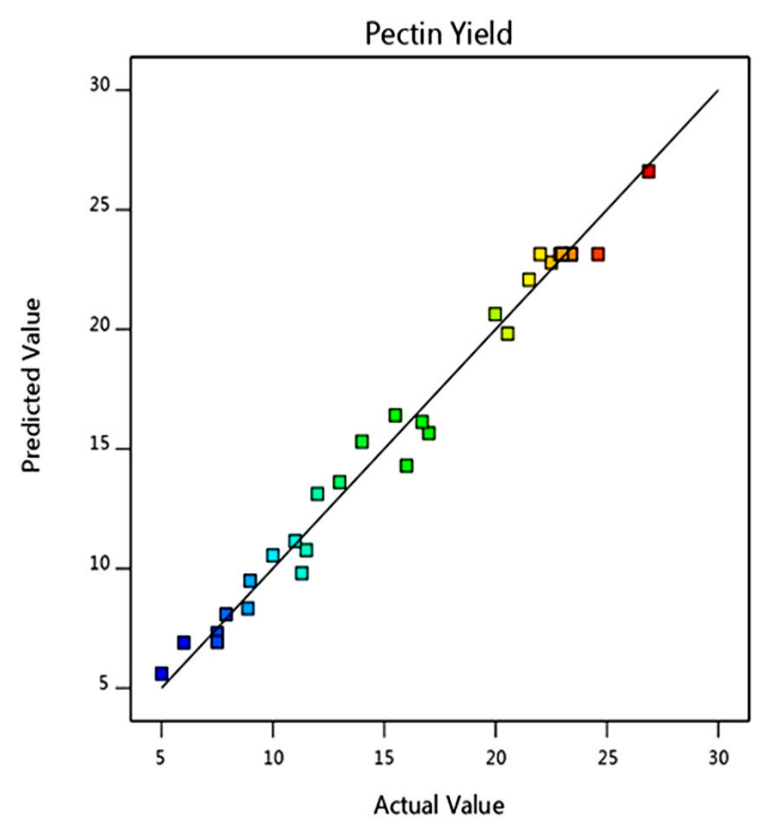

Figure 1. Actual value via CCD prediction of the yield

The outcome of ANOVA for the model is demonstrated in Table 3. It is shown that the model is substantial with a $95 \%$ level of confidence when the value of $\mathrm{P}$ for model is below 0.05 [26]. As demonstrated, the value of $\mathrm{P}$ was below 5\% that shows the model was strongly significant in (Table 3 ).

The suggested quadratic model equation is based on the results of ANOVA as indicated in Eqs. (13), in terms of code by applying multiple regression analysis on the experimental data for prediction of the yield.

The quadratic models of regression analysis suggested by the model were expressed as follows in terms of coded factors.

Pectin Yield $(\%)=+24.18-029 \mathrm{~A}-4.37 \mathrm{~B}+$ $1.59 \mathrm{C}+0.03 \mathrm{D}-0.21 \mathrm{AB}-0.07 \mathrm{AC}-0.11 \mathrm{AD}-$ $1.29 \mathrm{BBC}+0.96 \mathrm{BD}-0.24 \mathrm{CD}-3.88 \mathrm{~A}^{2}-$ $2.26 \mathrm{~B}^{2}-1.12 \mathrm{C}^{2}-1.68 \mathrm{D}^{2}$
Table 3. ANOVA analysis for the quadratic result.

\begin{tabular}{llllll}
\hline \multicolumn{1}{c}{ Source } & \multicolumn{1}{c}{ SS } & DF & \multicolumn{1}{c}{ MS } & F-Value & P-Value \\
\hline Model & 1160.73 & 14 & 82.91 & 1305.30 & $0.0001^{* * *}$ \\
A & 1.86 & 1 & 1.86 & 29.27 & $0.0001^{* * *}$ \\
B & 362.96 & 1 & 362.96 & 5714.31 & $0.0001^{* * *}$ \\
C & 48.42 & 1 & 48.42 & 762.26 & $0.0001^{* * *}$ \\
D & 0.02 & 1 & 0.02 & 0.32 & $0.5791^{*}$ \\
AB & 0.63 & 1 & 0.63 & 9.95 & $0.0065^{* *}$ \\
AC & 0.07 & 1 & 0.07 & 1.15 & $0.3010^{*}$ \\
AD & 0.19 & 1 & 0.19 & 3.05 & $0.1013^{*}$ \\
BC & 34.80 & 1 & 34.80 & 547.81 & $0.0001^{* * *}$ \\
BD & 14.29 & 1 & 14.29 & 224.95 & $0.0001^{* * *}$ \\
CD & 0.86 & 1 & 0.86 & 13.48 & $0.0023^{* *}$ \\
$\mathrm{~A}^{2}$ & 414.24 & 1 & 414.24 & 6521.56 & $0.0001^{* * *}$ \\
$\mathrm{~B}^{2}$ & 91.14 & 1 & 91.14 & 1434.84 & $0.0001^{* * *}$ \\
$\mathrm{C}^{2}$ & 22.57 & 1 & 22.57 & 355.40 & $0.0001^{* * *}$ \\
$\mathrm{D}^{2}$ & 77.15 & 1 & 77.15 & 1214.57 & $0.0001^{* * *}$ \\
Residual & 0.95 & 15 & 0.06 & & \\
Lack of Fit & 0.78 & 9 & 0.09 & 2.95 & $0.1004^{*}$ \\
Pure Error & 0.18 & 6 & 0.03 & & \\
Total & 1161.68 & 29 & & & \\
\hline $\mathrm{R}^{2}$ & & & 0.968 & & \\
AdJ.R & & & 0.948 & & \\
Pred. R & & & 0.958 & & \\
Ade Pr. & & & 26.361 & & \\
Std. Dev. & & & 1.160 & & \\
Mean & & & 15.810 & & \\
C.V.\% & & & 7.330 & & \\
\hline & & & & & \\
\hline
\end{tabular}

Degree of freedom (DF), Sum of square (SS), Average square (AS)

Effect of Process Variables on the Yield of Pectin

The result in Table 3 and Eq. (13) separately showed that all variables were widely effective in the extraction process, except the liquid-solid ratio does not significant. $\mathrm{pH}$ solution should be considered more than the other factor since it was the most significant indicator in the extraction process (Table 3 and Eq. 13). Apart from the liquid-solid ratio and $\mathrm{pH}$, the combinations versus ultrasound power and $\mathrm{pH}$ had a highly influential on the yield. A 3D plots were demonstrated below for more exploration in the relationship between response and parameters. At the least $\mathrm{pH}$ solution and highest ultrasound power, the maximum 
extraction yield was attained. This means, high acidic media brought the pectin leakage from the plant substance and in consequence, increased the extraction efficiency [13].
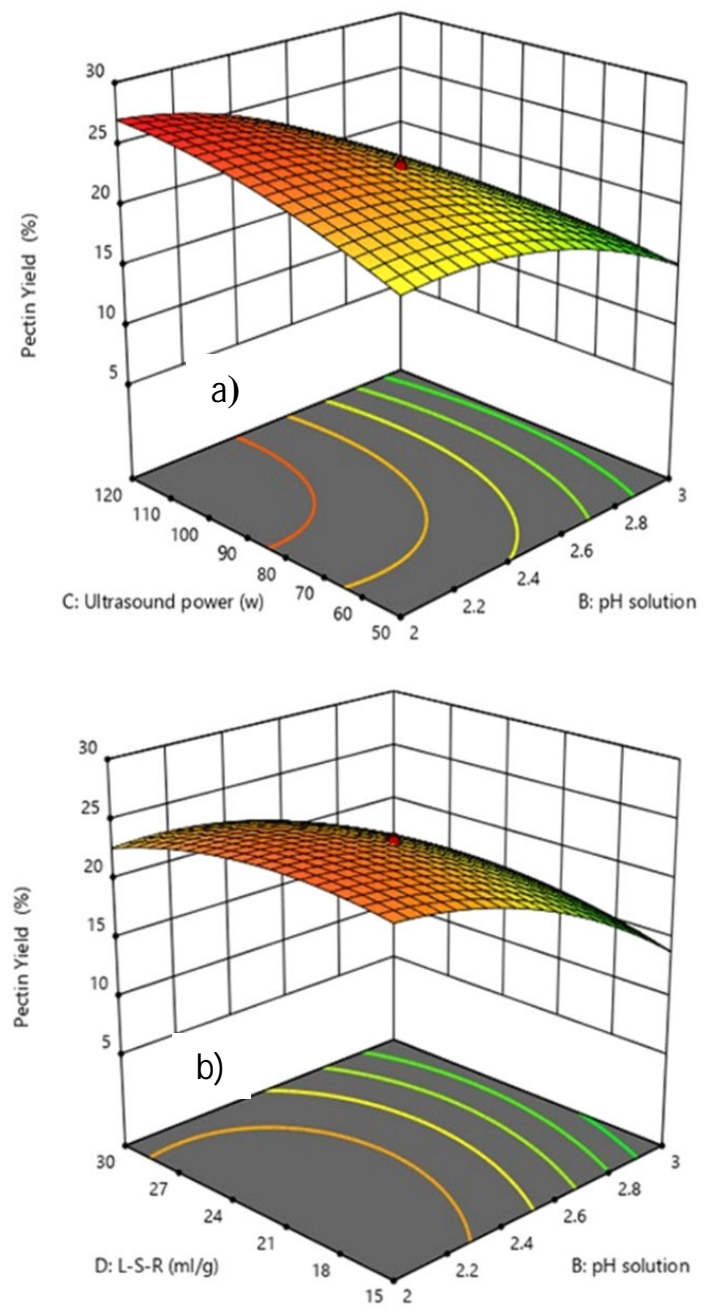

Figure 2. pH Vs Ultrasound (a) and pH Vs Liquid-solid ratio on the yield (b)

Another efficient variable that had a direct influence on the extraction was ultrasound power. Fig. 3a reveals that ultrasound power was better to yield when enhancing the ultrasound power. This result may be related to the cavitation consequences of ultrasound waves and this cavitation bring up the solvent insight into the intercellular substance of the plant and thereby upgrades the pectin escapees leads to an increase the extraction efficiency [27] .

The irradiation time is another important process parameter that affects the yield of pectin significantly compared to the liquid-solid ratio in this study. Due to the creation of the cavitation bubble by ultrasound waves supports the disruption of the cell wall of the plant to increase the extraction efficiency and produce swelling and hydrate the plant material in the initial stage [5]. The yield of pectin did not highly influence with liquid-solid ratio; it was affirmed by the outcomes of the ANOVA (P <5\%) and Eq. (13). It also seen that changing the ambit of analyze greater than $22.51: 1 \mathrm{~mL} / \mathrm{g}$ of liquidsolid ratio, might be contribute to an unlike decision concerning the engagement of this exploiting variables in the cavitation impact happening in an extraction helped by ultrasound wave [27]. In addition, for the similar process parameters, similar optimum conditions were investigated for pectin extracted from orange peels using ultrasound assisted technique. While the higher yield of pectin $(27.8 \pm 02 \%$.) was investigated experimentally from orange wastes using ultrasound assisted method in the current study, compared to pectin extracted from orange peels $(26.87 \%)$. This is due to the orange wastes containing both bark (peels) of the orange and inside parts of the orange left after used [28].

\section{Artificial neural network (ANN) based modeling}

The ANN anticipation was developed applying the information obtained from CCD (Table 1). The artificial neural network model was done by the selection of the reserve algorithm of training, determining the optimum value of the neuron, and validation of the model. Levenberg-Marquardt artificial neural network corresponding tool and 
Transfer Function, TANSIG 4-8-1 (the input, neurons in the hidden and output) layer model was implemented. To examine the insertion of the prediction from the created models; the experimental values were compared with the anticipated result of central composite design and artificial neural network models. It is shown that the anticipated yield by CCD and ANN model has closely concurred with the actual values (Table 4). However, the prediction capability of ANN is greater than the prediction of CCD.

Table 4. Result of CCD and ANN prediction on sugar yields.

\begin{tabular}{|c|c|c|c|}
\hline $\begin{array}{l}\text { Run } \\
\text { number }\end{array}$ & $\begin{array}{c}\text { Experimental } \\
\text { value }\end{array}$ & $\begin{array}{c}\text { CCD } \\
\text { Prediction }\end{array}$ & $\begin{array}{c}\text { ANN } \\
\text { Prediction }\end{array}$ \\
\hline 1 & 20.01 & 20.11 & 20.30 \\
\hline 2 & 9.9 & 9.81 & 9.93 \\
\hline 3 & 23.23 & 23.16 & 23.17 \\
\hline 4 & 11.3 & 11.34 & 11.91 \\
\hline 5 & 10.3 & 10.31 & 10.41 \\
\hline 6 & 16.3 & 16.55 & 16.80 \\
\hline 7 & 16.7 & 16.45 & 16.65 \\
\hline 8 & 7.3 & 7.15 & 7.38 \\
\hline 9 & 22.57 & 22.51 & 22.53 \\
\hline 10 & 8.5 & 8.27 & 8.62 \\
\hline 11 & 5.75 & 5.46 & 5.77 \\
\hline 12 & 16.7 & 17.55 & 17.60 \\
\hline 13 & 23.4 & 23.19 & 23.20 \\
\hline 14 & 15.01 & 15.95 & 14.96 \\
\hline 15 & 15.8 & 15.55 & 15.98 \\
\hline 16 & 26.5 & 27.13 & 28.33 \\
\hline 17 & 15 & 14.2 & 15.06 \\
\hline 18 & 10 & 10.3 & 10.45 \\
\hline 19 & 8.31 & 8.72 & 8.97 \\
\hline 20 & 8.1 & 8.1 & 7.58 \\
\hline 21 & 23.1 & 23.19 & 23.17 \\
\hline 22 & 20.54 & 20.65 & 20.75 \\
\hline 23 & 22.5 & 22.71 & 22.85 \\
\hline 24 & 23 & 23.16 & 23.16 \\
\hline 25 & 16.4 & 16.2 & 14.36 \\
\hline 26 & 8.88 & 8.06 & 9.12 \\
\hline 27 & 22.99 & 23.17 & 23.18 \\
\hline 28 & 23.4 & 23.19 & 23.21 \\
\hline 29 & 23.23 & 23.15 & 23.16 \\
\hline 30 & 11.5 & 11.71 & 11.91 \\
\hline
\end{tabular}

The actual value and predicted value of the ANN was also plotted in Fig 3. This graph consists of the linear line shows, $y=x$, meaning, the anticipated value of the pectin yield is equivalent to the experimental value with the highest level of correlations coefficient compared to the prediction achieved the utilizing CCD shown in Fig. 1.

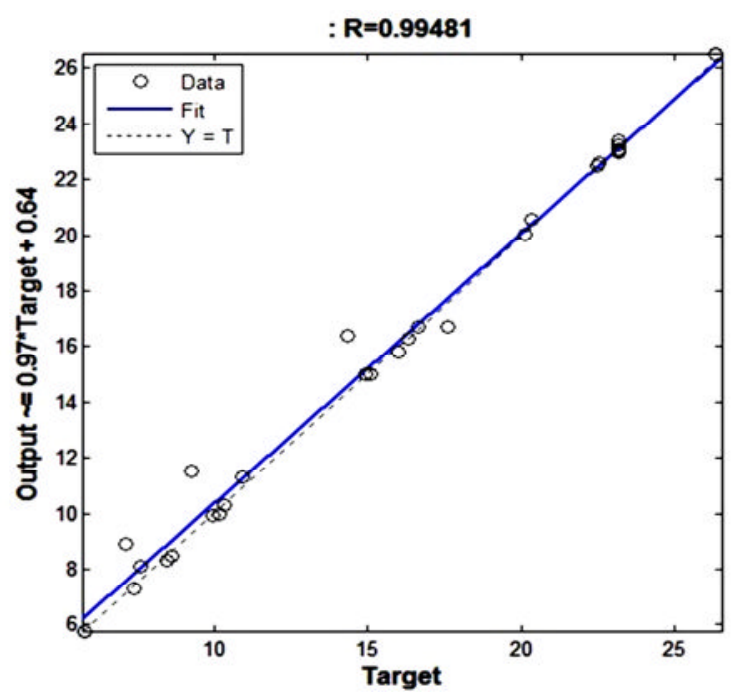

Figure 3. Experimental value versus ANN prediction of pectin yield

The relationship between the parameters as specified by the correlation coefficient $(\mathrm{R})$, meaning a unit number of the coefficient of correlation implies a perfect relationship between variables while a zero $(0)$ number indicates the non-existence of a linearity between the parameters [29]. Statistical performance indices were assumed in finding the higher anticipation power of the model and decided using Eqs. (2-6), to compare the ANN and CCD prediction efficiency as shown in Table 5. The best solution was chosen based on the highest coefficient of correlation and least MSE for training, testing, and validation. Therefore, after the larger number of training, 8 numbers of neurons were selected depending on, the best ANN performance indexes as indicated in Fig. 3 and 4. Additionally, the selected values of performance of training, testing, and validation are indicated in supplementary material Table 2. Fig. 4 shows the regression plots of the training, validation, test, and all Rvalue with the $\mathrm{LM}$ algorithm. 
Training: $\mathbf{R}=0.99992$

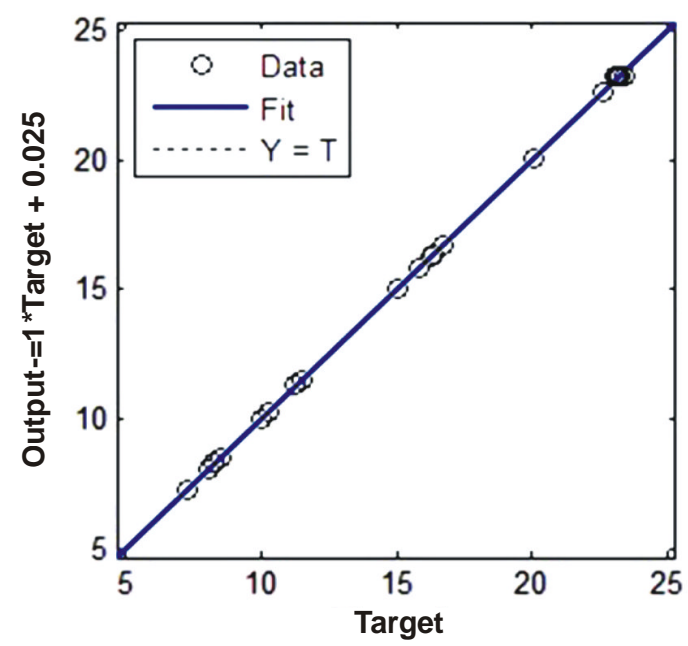

Test: $\mathbf{R}=0.98476$

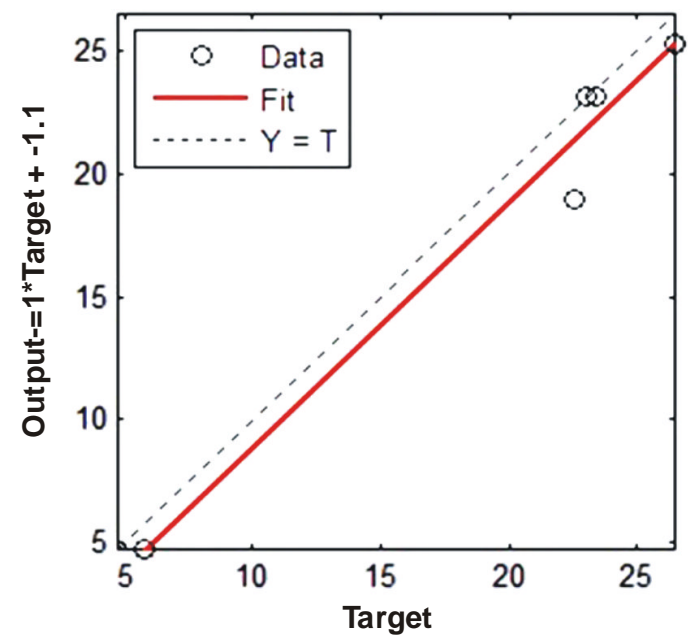

Figure 4. Correlation coefficients for mean pectin yield (ANN)

Evaluation of central composite design and artificial neural network performance

To detect the best model that accurately predicts the extracted yield of pectin, the anticipation ability of the central composite design and artificial neural network models, the statistical performance indexes were evaluated for both models (Table 5). The R-result of CCD and ANN model are 0.967 and 0.994, respectively. Concurring to the values of $R$, the prediction degree of the artificial neural network model has a higher
Validation: $\mathbf{R}=99738$

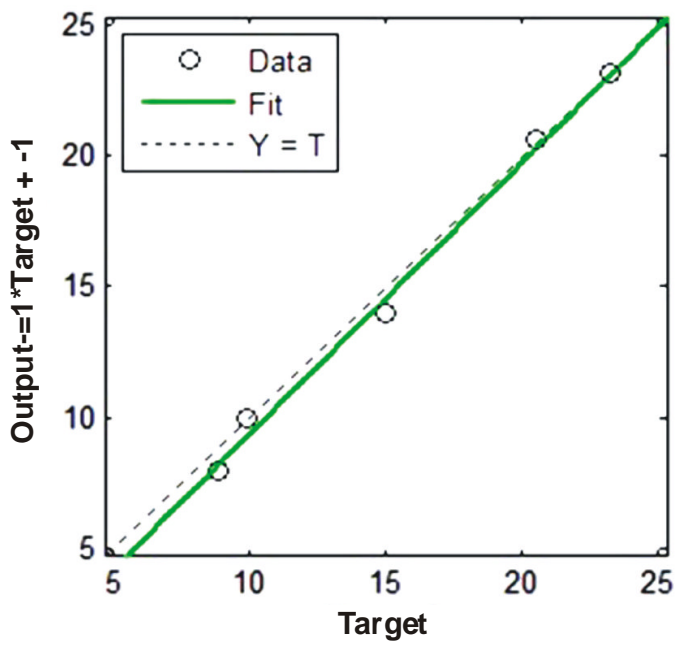

All: $\mathbf{R}=\mathbf{0 . 9 9 3 3 3}$

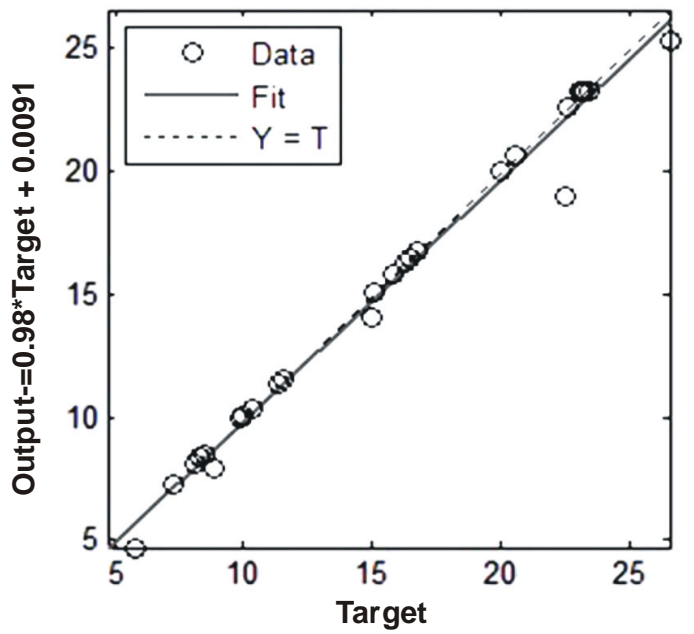

prediction capacity compared to the CCD model. Additionally, ANN indicates the lower statistical performance indexes, as shown in Table 5, compared to CCD. Depending up on the predictive capacity, it is shown that the ANN model can captivate the degree of complexity that appears between the reception and input process variables. In any case, to depict the process, huge data are fundamental for ANN preparing. There are numerous components, such as the input-output, neurons, also learning variables that impact fruitful ANN preparing. These components 
are to be decided by a trial and error strategy and repeated preparing the training reenactment, and this is time expending. On the other hand, the response surface methodology model requires the least number of tests to formulate the model.

Table 5. CCD and ANN models Statistical performance indicators.

\begin{tabular}{lcc}
\hline Variables & CCD & ANN \\
\hline R & 0.968 & 0.995 \\
MSE & 0.027 & 0.012 \\
SEP & 0.006 & 0.002 \\
MAE & 0.413 & 0.132 \\
AAD & 0.321 & 0.211 \\
\hline
\end{tabular}

\section{Product Characterization FT-IR haracterization}

The FTIR range of the extricated pectin from orange waste is appeared in Fig. 4. The broad extending, strong assimilation region between 4000 and 500 $\mathrm{cm}^{-1}$ (e.g., $3434 \mathrm{~cm}^{-1}$ ) is typically hydroxyl group $(\mathrm{O}-\mathrm{H})$ and is related to vibrational fashions of intra and inter-molecular $\mathrm{H}_{2}$ attaches of the Galacturonic acid polymer in terms of free hydroxyl bunches and attached $\mathrm{O}-\mathrm{H}$ groups of carboxylic acids [30]. The absorption peak at $2937 \mathrm{~cm}^{-1}$ (3000-2800 $\left.\mathrm{cm}^{-1}\right)$ was designated to the $\mathrm{C}-\mathrm{H}\left(\mathrm{CH}, \mathrm{CH}_{2}\right.$, and $\mathrm{CH}_{3}$ ) extending oscillations [31]. The presence of intense peaks within the assimilation zone between 950 and $1450 \mathrm{~cm}^{-1}$ can be due to the vibrations associated with glycosidic bonds and pyranoid rings [32]. However, some studies pointed out that the bonds show at approximately $800-1500 \mathrm{~cm}^{-1}$ assigned to a unique fingermark region with particular functional bunches property of polysaccharides [30].

Depending on the detected information, the biopolymer pectin extricated from orange wastes could be a polysaccharide-rich linked with poly $\alpha$-Dgalacturonic acid. The extracted pectin in present experiment confirmed to absorption peaks with the pectin extracted from apple pomace and citrus peel by subcritical water method [32].

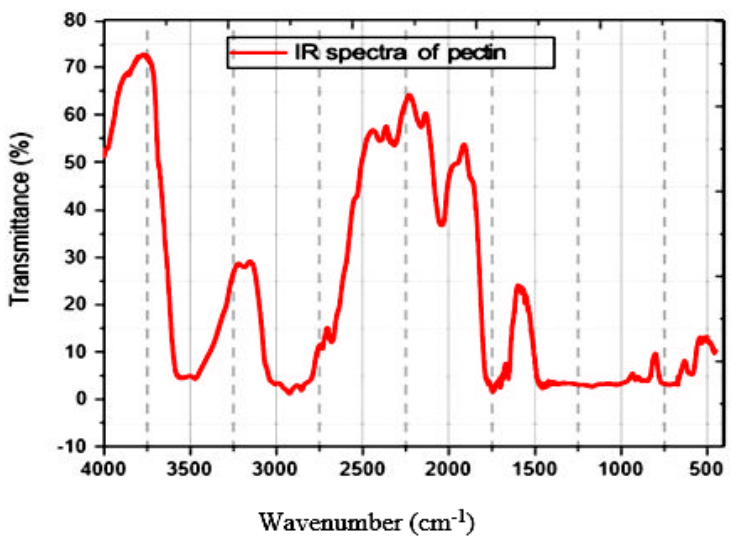

Figure 5. FTIR spectra of the pectin extracted from orange waste by ultrasound-assisted technique

To represent the level to which the pectin molecules subsist, esterification degree (DE) is very important indicator. In this study, the result has shown that, the higher DE $(>50$ $\%)$ and it is considered as higher methoxyl product. Pectin indicates a higher tendency to form gel rapidly at a higher temperature and greatly influences the lipid substance when the $\mathrm{DE}$ is above 50\% [33].

Another important criterion to classify the functional behavior of pectin is the equivalent weight $(\mathrm{EW})$, since the gelling tendency of individual pectin is linked very closely with EW [34]. The higher EW, has greater gel formation, while the lower EW, indicates larger partial degradation of the pectin, which is non-profitable [35] and thus the raise or diminish of the EW could be used to indicate the pectin property [18]. The average EW of pectin in this study was found to be $604.74 \mathrm{kDa}$, closest to data indicated by Altaf et al. [36], that EW of extracted pectin from papaya fruits using $\mathrm{HCl}$. He stated that pectin produced at lower $\mathrm{pH}$ value, has higher $\mathrm{EW}$, since lower $\mathrm{pH}$ can lead polymerization of pectin into an extended chain, and in turn, decrease the amount of free acid. 
The methoxyl content (MC) is a tool used to control the setting time, the gel strength and to find the functional properties of pectin [37]. P. Kanmani [38], established that, depending on the origin of raw material used and method of extraction, the MC of this substance usually ranged from $0.02-0.12$. In this study, $6.23 \%$ of MC was achieved. Since the MC was below $12 \%$, that indicates it is suitable in terms of character, and besides due to its higher DE.

Anhydrouronic acid, pectin must contain at least $65 \%$ of galacturonic acid [39], since it is used to represent the gelling tendency of the pectin. The higher result indicates the produced pectin has lower contents of protein substance. Because the more soluble pectin appeared effectively for the lower protein content [40]. In the current study, $68.25 \%$ of Anhydrouronic acid was achieved above the minimum value specified by FAO [39] for commercial application of pectin.

Acetyl value (AV); the pre-study showed that the moussing tendency of pectin substance diminished by raising in the level of acetylation and sample holding $0.035-0.04 \%$ acetyl brings debile gels when moussing capacity reestablished at about 0.024 acetyl value [18]. In this study, the result indicates that pectin has a good gelling capacity of $0.371 \%$. The properties of pectin are shown in Table 6.

Table 6. Properties of pectin extracted from orange wastes.

\begin{tabular}{lccc}
\hline Parameters (\%) & $\begin{array}{c}\text { Current } \\
\text { value }\end{array}$ & \multicolumn{2}{c}{ Literature Value } \\
\hline Methoxyl content & 6.21 & 6.23 & 8.875 \\
Anhydrouronic acid & 68.5 & 70.91 & 60.95 \\
Acetyl content & 0.37 & 0.4 & 0.455 \\
Degree of esterification & 62.5 & 60.4 & 55.01 \\
Equi valent weight & 610.56 & 599.74 & - \\
\end{tabular}

\section{Conclusion}

Central composite design and artificial neural network were employed to extract pectin from orange wastes utilizing the ultrasound-assisted method. The best conditions for the process variables were; 22.51:1 $\mathrm{mL} / \mathrm{g}$ of liquid-solid ratio, 1.52 of $\mathrm{pH}$ solution, $22.53 \mathrm{~min}$ of irradiation time and $155.6 \mathrm{~W}$ of ultrasound power. At these points, $27.8 \pm 0.2 \%$ pectin yield was achieved experimentally, while 27.13 and $28.33 \%$ of yield were achieved by prediction of central composite design and artificial neural network model, respectively. A pH study indicated that as $\mathrm{pH}$ increases, the yield of pectin decreases. In contrast, the extraction efficiency was also enhanced by enhancing the ultrasound power. The execution of artificial neural network models for pectin yield was found to be better in terms of the higher prediction and performance indexes. However, huge data and learning variables are necessary for artificial neural network training, which is time consuming. The extracted pectin has a higher degree of esterification, and it is grouped to high methoxyl pectin. For the same conditions, the yield of pectin extracted from orange waste is higher than pectin extracted from orange peels since the orange waste contains both internal and external parts of the orange leftover.

\section{Acknowledgments}

The author expresses his gratitude to Jimma University Institute of Technology and Addis Ababa institute of technology for this research.

\section{Conflict of Interest}

The author declares no conflict of interest, including any financial, personal or other relationships with other people or organizations. 


\section{References}

1 E. R. Pinheiro, I. M. D. A. Silva, L. V. Gonzaga, E. R. Amante, R. F. Teófilo, M. M. C. Ferreira and R. D. M. C. Amboni, Bioresour. Technol., 99 (2008) 5561. https://doi.org/10.1016/j.biortech.2007.1 0.058 .

2 D. N. Abang Zaidel, N. H. Hamidon and N. Mat Zahir, Acta Hortic., 1152 (2017) 211.

https://doi.org/10.17660/ActaHortic.201 7.1152.29.

3 S. S. Hosseini, F. Khodaiyan and M. S. Yarmand, Int. J. Biol. Macromol., 82 (2016) 920.

https://doi.org/10.1016/j.ijbiomac.2015. 11.007.

4 P. Methacanon, J. Krongsin and C. Gamonpilas, Food Hydrocoll., 35 (2014) 383.

https://doi.org/10.1016/j.foodhyd.2013.0 6.018.

5 C. S. Shivamathi, I. G. Moorthy, R. V. Kumar, M. Rahul, J. P. Maran, R. S. Kumar and P. Varalakshmi, Carbohydr. Polym., 225 (2019) 115240.

https://doi.org/10.1016/j.carbpol.2019.1 15240.

6 J. S. Yang, T. H. Mu and M. M. Ma, Food Chem., 289 (2019) 351. https://doi.org/10.1016/j.foodchem.2019 .03 .027$.

7 M. Marić, A.N. Grassino, Z. Zhu, F.J. Barba, M. Brnčić and S. Rimac Brnčić, Trends Food Sci. Technol., 76 (2018) 28.

https://doi.org/https://doi.org/10.1016/j.ti fs.2018.03.022.

8 A. A. Sundarraj, R. Thottiam Vasudevan and G. Sriramulu, Int. J. Biol. Macromol. 106 (2018) 698.

https://doi.org/https://doi.org/10.1016/j.ij biomac.2017.08.065.

9 M. Khayet, C. Cojocaru and M. Essalhi,
J. Memb. Sci., 368 (2011) 202.

https://doi.org/10.1016/j.memsci.2010.1 1.030 .

10 S. M. Ghoreishi, A. Hedayati and S. O. Mousavi, J. Supercrit. Fluids., 112 (2016) 57.

https://doi.org/10.1016/j.supflu.2016.02. 006.

11 S. Lahmiri and S. Bekiros, Chaos, Solitons \& Fractals., 133 (2020) 109641.

https://doi.org/https://doi.org/10.1016/j.c haos.2020.109641.

12 Z. Chen, K. Gryllias and W. Li, Mech. Syst. Signal Process., 133 (2019) 106272.

https://doi.org/https://doi.org/10.1016/j.y mssp.2019.106272.

13 S. S. Hosseini, F. Khodaiyan, M. Kazemi and Z. Najari, Int. J. Biol. Macromol., 125 (2019) 621.

https://doi.org/10.1016/j.ijbiomac.2018. 12.096.

14 A. E. Atabani, A. H. Al-Muhtaseb, G. Kumar, G. D. Saratale, M. Aslam, H. A. Khan, Z. Said and E. Mahmoud, Fuel., 254 (2019) 115640.

https://doi.org/https://doi.org/10.1016/j.f uel.2019.115640.

15 V. Florencia, O. V López and M. A. García, Compos. Part B. Eng., 182 (2020) 107653.

https://doi.org/https://doi.org/10.1016/j.c ompositesb.2019.107653.

16 S. Muthusamy, L. P. Manickam, V. Murugesan, C. Muthukumaran and A. Pugazhendhi, Int. J. Biol. Macromol., 124 (2019) 750.

https://doi.org/10.1016/j.ijbiomac. 2018. $\underline{11.036 .}$

17 B. L. Chua, S. F. Tang, A. Ali and Y. H. Chow, SN Appl. Sci., 2 (2020).

https://doi.org/10.1007/s42452-0202415-y.

18 H. Mohamed, MOJ Food Process. Technol., 2 (2016) 31. 
https://doi.org/10.15406/mojfpt.2016.02. 00029.

19 O. A. Fakayode and K. E. Abobi, J. Anal. Sci. Technol., 9 (2018). https://doi.org/10.1186/s40543-0180151-3.

20 E. Kliemann, K. N. De Simas, E. R. Amante, E. S. Prudêncio, R. F. Teófilo, M. M. C. Ferreira and R. D. M. C. Amboni, Int. J. Food Sci. Technol., 44 (2009) 476.

https://doi.org/10.1111/j.1365-

2621.2008.01753.x.

21 K. Asgari, M. Labbafi, F. Khodaiyan, M. Kazemi and S. S. Hosseini, Int. J. Biol. Macromol., 152 (2020) 1274.

https://doi.org/https://doi.org/10.1016/j.ij biomac.2019.10.224.

22 Y. Yang, Z. Wang, D. Hu, K. Xiao and J.-Y. Wu, Food Hydrocoll., 79 (2018) 189.

https://doi.org/https://doi.org/10.1016/j.f oodhyd.2017.11.051.

23 K. Kaderides, L. Papaoikonomou, M. Serafim and A. M. Goula, Chem. Eng. Process.-Process Intensif., 137 (2019) 1. https://doi.org/https://doi.org/10.1016/j.c ep.2019.01.006.

24 R. Chen, C. Jin, Z. Tong, J. Lu, L. Tan, L. Tian and Q. Chang, Carbohydr. Polym., 136 (2016) 187.

https://doi.org/10.1016/j.carbpol.2015.0 9.036.

25 S. S. Hosseini, F. Khodaiyan and M. S. Yarmand, Carbohydr. Polym., 140 (2016) 59.

https://doi.org/10.1016/j.carbpol.2015.1 2.051.

26 X. Zhang, J. Chen, M. Mao, H. Guo and Y. Dai, Int. J. Biol. Macromol., 67 (2014) 318.

https://doi.org/10.1016/j.ijbiomac.2014. $\underline{03.039 \text {. }}$

27 I. G. Moorthy, J. P. Maran, S. Ilakya, S. L. Anitha, S. P. Sabarima and B. Priya, Ultrason. Sonochem., 34 (2017) 525. https://doi.org/10.1016/j.ultsonch.2016.0 6.015 .

K. B. Hundie, Eu. J. Material Scie. Eng., 8 (2020) 69.

https://doi.org/10.30954/2322-

0465.2.2020.1.

29 C. Y. Cheok, N. L. Chin, Y. A. Yusof, R. A. Talib and C. L. Law, Ind. Crops Prod., 40 (2012) 247.

https://doi.org/10.1016/j.indcrop.2012.0 3.019 .

30 S. Q. Liew, N. L. Chin and Y. A. Yusof, Agric. Sci. Procedia., 2 (2014) 231. https://doi.org/10.1016/j.aaspro.2014.11. 033.

31 S. M. T. Gharibzahedi, B. Smith and Y. Guo, Int. J. Biol. Macromol., 136 (2019) 275.

https://doi.org/10.1016/j.ijbiomac.2019. $\underline{06.040 .}$.

32 S. Q. Liew, G. C. Ngoh, R. Yusoff and W. H. Teoh, Int. J. Biol. Macromol., 93 (2016) 426.

https://doi.org/10.1016/j.ijbiomac.2016. 08.065 .

33 Z. Rahmani, F. Khodaiyan, M. Kazemi and A. Sharifan, Int. J. Biol. Macromol., 147 (2020) 1107.

https://doi.org/10.1016/j.ijbiomac.2019. 10.079 .

34 M. Dominiak, K. M. Søndergaard, J. Wichmann, S. Vidal-Melgosa, W. G. T. Willats, A. S. Meyer and J. D. Mikkelsen, Food Hydrocoll., 40 (2014) 273.

https://doi.org/10.1016/j.foodhyd.2014.0 3.009 .

35 F. Hardy, Biochem. J., 18 (1924) 283. https://doi.org/10.1042/bj0180283.

36 U. Altaf, G. Immanuel and F. Iftikhar, Int. J. Sci. Eng. Technol., 3 (2015) 1. https://doi.org/10.2348/ijset07150970.

37 J. P. Maran, B. Priya, Carbohydr. Polym., 115 (2015) 732.

https://doi.org/10.1016/j.carbpol.2014.0 7.058. 
38 P. Kanmani, Iran. J. Energy Environ., 540 (2014) 303.

https://doi.org/10.5829/idosi.ijee.2014.0 5.03.10.

39 W. G. T. Willats, J. P. Knox and J. D. Mikkelsen, Trends Food Sci. Technol., 17 (2006) 97.

https://doi.org/10.1016/j.tifs.2005.10.008.
C. L. Adam, S. W. Gratz, D. I. Peinado, L. M. Thomson, K. E. Garden, P. A. Williams, A. J. Richardson and A. W. Ross, PLoS One., 11 (2016) 1.

https://doi.org/10.1371/journal.pone.015 5871. 